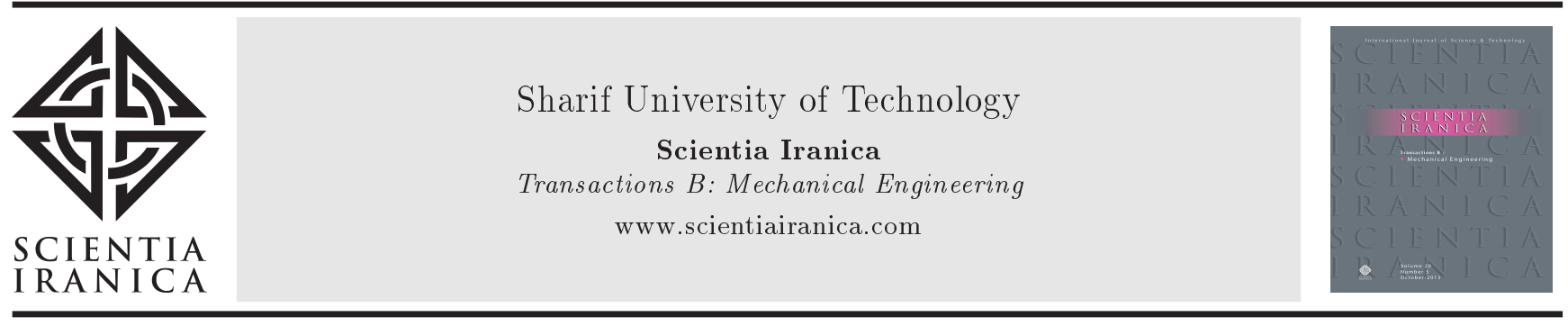

\title{
The effect of outer diameter of multi-walled carbon nanotubes on fracture behavior of epoxy adhesives
}

\author{
H. Khoramishad ${ }^{\mathrm{a}, *}$, M. Khakzad ${ }^{\mathrm{a}}$ and M. Fasihi $^{\mathrm{b}}$ \\ a. School of Mechanical Engineering, Iran University of Science and Technology, Narmak, 16846, Tehran, Iran. \\ b. School of Chemical Engineering, Iran University of Science and Technology, Narmak, 16846, Tehran, Iran. \\ Received 12 June 2016; received in revised form 3 August 2016; accepted 15 October 2016
}

\section{KEYWORDS \\ Multi-walled carbon nanotubes; \\ Toughened adhesives; \\ Fracture energy; \\ Cohesive zone model; \\ Double cantilever \\ beam.}

\begin{abstract}
In this paper, the influence of the outer diameter of multi-walled carbon nanotubes (MWCNTs) on the fracture behavior of epoxy adhesives was investigated experimentally and numerically. MWCNTs with three different outer diameters of less than 8, 20-30, and 50-80 nm were used to toughen the epoxy adhesive. Double Cantilever Beam specimens were tested to determine the fracture energy. The results indicated that improvement in the adhesive fracture resistance by introducing MWCNTs was considerably dependent on the outer diameter of MWCNTs. Toughening the epoxy adhesive by incorporating MWCNTs with $8 \mathrm{~nm}$ diameter improved the adhesive fracture energy three times higher compared to the MWCNTs with larger diameters. The SEM fractography of the fracture surfaces was also utilized to assess the governing fracture mechanisms occurred in the toughened epoxy adhesives. Moreover, a cohesive zone model was used for numerical investigation of the effect of the MWCNT diameter on the damage behavior of epoxy adhesives.
\end{abstract}

(C) 2017 Sharif University of Technology. All rights reserved.

\section{Introduction}

Adhesively bonded joints have attracted considerable attention in various industries, such as aerospace, construction, and automotive, due to their superior advantages over traditional joints such as low structure weight, low fabrication cost, high strength, and low stress concentration. Incorporating nano-sized fillers into adhesive structures is an efficient way of enhancing the mechanical properties [1]. There are several nanoparticles of different shapes and different materials, such as nano-silica [2], nano-rubber [3], nano-clay [4], carbon nano-tube [5], and graphene

\footnotetext{
*. Corresponding author. Tel.: +9821 77240540-50,

Ext.: 8988; Fax: +9821 7r2440488

E-mail addresses: Khoramishad@iust.ac.ir (H.

Khoramishad); moeinkhakzad@yahoo.com (M. Khakzad);

mfasihi@iust.ac.ir (M. Fasihi).
}

doi: $10.24200 /$ sci. 2017.4504 nano-platelet [6], which can be used for improving the mechanical properties of adhesive and composite materials. Nano-fillers with different materials and geometrical characteristics have different effects on the material properties. The nano-fillers made of carbon material are of high importance due to their exclusive characteristics. In recent years, many researchers investigated the polymers reinforced by nano-fillers. Several different materials, such as thermoplastic film, thermoplastic particles, chopped fibres, glass/epoxy prepreg, thermoset adhesive film, thermoset adhesive particles, and short aramid fibers, have been used for increasing the critical energy release rate [7]. Yasaee et al. [7] added several kinds of second-phase additives, such as thermoplastic and thermoset films, to improve the strain energy release rate $\left(G_{I C}\right)$. The results showed that the thermoset and thermoplastic films increased the strain energy release rate by 43 and 79 percentages, respectively. Sun et al. [8] used short aramid fibers with different lengths to improve the 
interfacial toughness of sandwich beam. They reported higher improvement in interfacial toughness due to adding shorter aramid fibers compared to the longer ones.

Dittanet and Pearson [9] studied the effect of silica nanoparticles of 23,74 , and $170 \mathrm{~nm}$ sizes on the fracture energy and fracture toughness of the epoxy resin. They showed that increasing the weight percentage of the nanoparticles increased the fracture toughness and reported the highest improvement for the size of $74 \mathrm{~nm}$. Zamanian et al. [10] investigated the size effect of the silica nanoparticles on the fracture toughness of an epoxy resin by considering nanoparticles with three different sizes of 12,20 , and $40 \mathrm{~nm}$. They achieved the maximum fracture toughness and fracture energy for the size of $12 \mathrm{~nm}$.

The employment of MWCNTs as the improver of polymer matrixes and epoxy adhesives has attracted great attention over the last decade due to the outstanding thermal and mechanical properties of MWCNTs. Gojny et al. [11] studied the effect of singlewall carbon nanotubes, double-wall carbon nanotubes, and multi-walled carbon nanotubes (MWCNTs) on the mechanical properties of the epoxy resin. They observed the highest fracture toughness improvement for the amino-functionalised double-walled carbon nanotubes at $0.5 \mathrm{wt} \%$. Meguid and Sun [12] added MWCNTs into the epoxy resins and studied their effect on tensile and shear properties. The results showed that adding MWCNTs beyond a limit weakened the interface strength.

The aluminum-bonded joints have found extensive applications in aerospace and automotive industries due to the lightness, high strength, and specific modulus. Meng et al. [13] performed a research study on the effect of elastomer particles of approximately $55 \mathrm{~nm}$ size on the toughness of epoxy adhesive. They used two different hardeners, namely J400 and J230, to cure the adhesives. Hardener J230 resulted in short molecular chain in the polymer, whereas hardener J400 produced a polymer with longer molecular chain. With increasing the molecular chain, the polymer became more ductile. They found that the effect of nanoparticles on the more ductile adhesive was much higher, compared to the other adhesive. They also examined the effect of the adhesive thickness, and found that thicker adhesive experiences higher improvement in fracture toughness due to the addition of nanoparticles. Wernik and Meguid [5] investigated the effect of carbon nanotubes (CNTs) with 13-18 nm diameter and 1-12 $\mu \mathrm{m}$ length on the toughness of an epoxy adhesive by testing the Double Cantilever Beam (DCB) specimen. They obtained $36 \%$ improvement in the fracture energy when $1 \mathrm{wt} \%$ CNTs was added to the adhesive. However, the fracture energy decreased by increasing the weight percentage of nanoparticles further. Gude et al. [14] studied the effect of the carbon nano-fibers and CNTs on an epoxy adhesive. They reported the improving effects of the carbon nano-fibers and CNTs on the adhesive fracture toughness, whereas addition of the nano-fillers did not impose considerable effect on the adhesive lap shear strength.

Damage modeling is of crucial importance in studying damage behavior of the adhesive and composite structures. The Cohesive Zone Model (CZM) has gained remarkable attention in damage modeling of different materials and problems. This model was successfully employed to study damage behavior of adhesive and composite structures under various loadings, such as quasi-static [15], fatigue [16], and creep [17] loading.

The purpose of this paper is to experimentally and numerically investigate the effect of the outer diameter of MWCNTs on the fracture energy and fracture behaviour of the epoxy adhesive under Mode I loading. The values of the adhesive fracture energies were obtained using BS 7991 standard. The SEM micrographs of the fracture surfaces of the neat and reinforced adhesive joints were used to determine the micro-mechanisms that caused the variation of fracture behaviors due to addition of MWCNTs with different sizes. Moreover, the cohesive zone model calibrated based on the experimental results was used to numerically study the effect of MWCNTs' size on the damage behavior of the adhesive.

\section{Materials}

\subsection{The two-component epoxy adhesive}

In this research, a two-component epoxy adhesive, named UHU Plus endfest 300, was used for manufacturing the adhesive joints. The binder and hardener were epoxy and aliphatic amines-based materials, respectively. The material properties of the adhesive are presented in Table 1. The mixture ratio of resin to hardener was 2 to 1 by weight according to the adhesive manufacturer catalogue.

Table 1. The material properties of the adhesive UHU plus endfest 300 [18].

\begin{tabular}{ccccc}
\hline $\begin{array}{c}\text { Chemical } \\
\text { basis }\end{array}$ & $\begin{array}{c}\text { Adhesive } \\
\text { technique }\end{array}$ & $\begin{array}{c}\text { Temperature } \\
\text { range for use }\end{array}$ & $\begin{array}{c}\text { Viscosity } \\
(\mathbf{m P a s . s e c})\end{array}$ & $\begin{array}{c}\text { Density } \\
\left(\mathbf{g} / \mathbf{c m}^{\mathbf{3}}\right)\end{array}$ \\
\hline \multirow{2}{*}{ Epoxy resin } & Wet adhesion & -40 to $+80^{\circ} \mathrm{C}$ & $\begin{array}{c}\text { Binder: } 40000 \\
\text { Hardener: } 30000\end{array}$ & $\begin{array}{c}\text { Binder: approx. } 1.2 \\
\text { Hardener: approx. } 0.96\end{array}$ \\
\hline
\end{tabular}




\subsection{The substrates}

To manufacture the adhesive joints, the substrates with the dimensions of $200 \times 25 \mathrm{~mm}$ were cut from a $4 \mathrm{~mm}$ thick sheet of Aluminum 6061-T6 and bonded using the unreinforced and reinforced adhesives. To achieve a proper adhesion between the substrates and adhesive, the bond surfaces of the substrates were prepared through several steps. First, the substrates were washed with water and soap, followed by cleaning with acetone and cotton clothes. Then, the substrates were acid etches for $30 \mathrm{~min}$ at $60^{\circ} \mathrm{C}$. Finally, the substrates were washed with distilled water.

\subsection{The multi-walled carbon nanotubes}

In this research, the carboxyl functionalized MWCNTs with three different outer diameters of less than $8 \mathrm{~nm}$, 20-30 nm, and 50-80 nm and purity of more than $95 \%$, manufactured by Neutrino Co., Iran, were utilized for reinforcing the adhesive joints. The properties of MWCNTs are listed in Table 2.

Clearly, investigation of the effect of outer diameter should be carried out when other factors remain the same. Apparently, by reducing the outer diameter of MWCNTs, to keep the volume or weight unchanged, more number of MWCNTs should be used leading to a wider total surface area. Therefore, higher $-\mathrm{COOH}$ content needs to be used for surface treatment. The important parameter that should be taken into consideration is the surface density of $-\mathrm{COOH}$ group to make sure that the surface conditions of the nanoparticles remain the same for different cases. Due to the tubular shape of MWCNTs, the ratio of the surface areas corresponding to MWCNTs with two different outer diameters is proportional to the inverse of the ratio of outer diameters. To keep the surface density of $-\mathrm{COOH}$ constant, the $-\mathrm{COOH}$ contents used for MWCNTs with different outer diameters should be different based on the inverse of the ratio of MWCNTs' outer diameters. For instance, if MWCNTs with outer diameters of 50$80 \mathrm{~nm}$ are taken as the base line in which the $-\mathrm{COOH}$ content is 0.49 wt\% (see Table 2), then the $-\mathrm{COOH}$ content for MWCNTs with outer diameters of 20-30 nm should be about $65 / 25 \times 0.49$ (i.e., $1.27 \mathrm{wt} \%$ ) in which 25 is the mean of 20 and 30 , or the $-\mathrm{COOH}$ content for MWCNTs with outer diameters of less than $8 \mathrm{~nm}$ should be about $65 / 8 \times 0.49$ (i.e., $3.98 \mathrm{wt} \%$ ). Therefore, the $-\mathrm{COOH}$ contents listed in Table 2 are reasonable in order to have constant surface density of $-\mathrm{COOH}$.

\section{Experimental}

\subsection{Specimen fabrication}

The effect of the MWCNT's outer diameter on the fracture energy of adhesive was studied by testing the Double Cantilever Beam (DCB) specimens. Therefore, the adhesive was reinforced by MWCNTs with different sizes. The MWCNTs were dispersed in the adhesive through several steps. Due to the high viscosity of the resin (40000 mPas.sec), the viscosity of the resin was reduced by increasing the resin temperature to $50^{\circ} \mathrm{C}$. Afterwards, MWCNTs were added to the resin and the mixture was stirred mechanically for $30 \mathrm{~min}$ at the rate of $180 \mathrm{rpm}$. After mixing, the sonication process was performed using the Bandelin sonopuls sonicator for 1 hour time operating at 70 watt and $1 \mathrm{sec}$ on/off cycle in order to reduce the generated heat from the sonication process. Moreover, the mixture was placed in a water and ice mixture during the sonication to reduce the mixture temperature. After sonication, the mixture was then placed in a vacuum chamber for $15 \mathrm{~min}$ to remove the trapped air bubbles. Finally, the curing agent was added to the mixture along with the mixture ratio of resin to hardener of 2 to 1 by weight, followed by mechanically mixing for $15 \mathrm{~min}$ at the rate of $180 \mathrm{rpm}$. Afterwards, the reinforced adhesive was spread out on the aluminum substrates and the adhesive joints were manufactured using a manufacturing fixture to guarantee the substrates alignment and the applied pressure during the curing process. The specimen thickness was controlled using wires having the thickness of $0.3 \pm 0.05 \mathrm{~mm}$. The specimens were cured in an oven for $40 \mathrm{~min}$ at the temperature of $110^{\circ} \mathrm{C}$. The adhesive joints were reinforced by MWCNTs with three outer diameters of less than $8 \mathrm{~nm}, 20-30 \mathrm{~nm}$, and $50-80 \mathrm{~nm}$ and with different weight percentages of $0.1,0.3$, and 0.5 .

The DCB specimens with the dimensions shown in Figure 1 were used to obtain the fracture energy under Mode I loading. Furthermore, a $12 \mu \mathrm{m}$ thick, non-stick polyethylene film was inserted as pre-crack.

\subsection{Determination of the fracture energy}

BS 7991 standard was used for determining the fracture energy of adhesive under Mode I loading using the Double Cantilever Beam specimens. According to this standard, three methods, including the simple beam, the corrected beam, and the experimental compliance

Table 2. The MWCNT properties.

\begin{tabular}{ccccc}
\hline $\begin{array}{c}\text { Outer } \\
\text { diameter }\end{array}$ & Length & $\begin{array}{c}- \text { COOH } \\
\text { content }\end{array}$ & $\begin{array}{c}\text { Specific surface } \\
\text { area }\left(\mathbf{m}^{\mathbf{2}} / \mathbf{g}\right)\end{array}$ & $\begin{array}{c}\text { Production } \\
\text { method }\end{array}$ \\
\hline$<8 \mathrm{~nm}$ & $10-30 \mu \mathrm{m}$ & $3.86 \mathrm{wt} \%$ & 500 & $\mathrm{CVD}$ \\
$20-30 \mathrm{~nm}$ & $10-30 \mu \mathrm{m}$ & $1.23 \mathrm{wt} \%$ & 110 & $\mathrm{CVD}$ \\
$50-80 \mathrm{~nm}$ & $10-30 \mu \mathrm{m}$ & $0.49 \mathrm{wt} \%$ & 40 & $\mathrm{CVD}$ \\
\hline
\end{tabular}




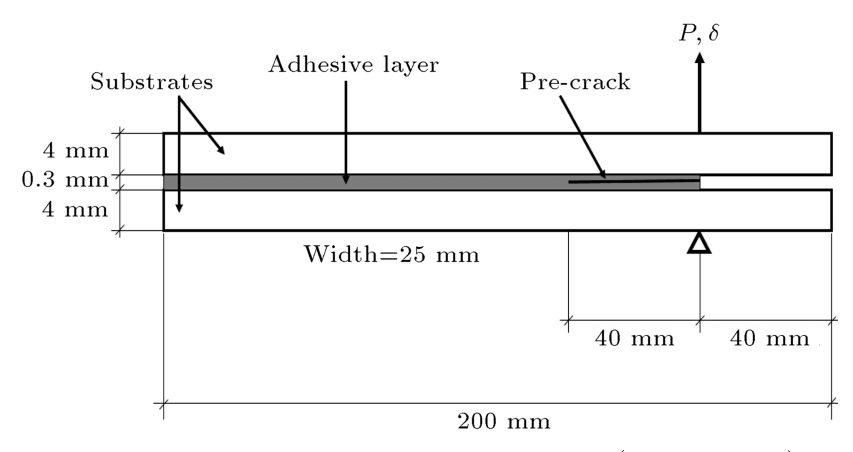

Figure 1. A schematic of DCB specimen (not in scale).

methods, can be used for obtaining the fracture energy under Mode I loading. According to the simple beam method, the fracture energy can be obtained using the crack length and applied load at every moment. According to the corrected beam method, the fracture energy can be obtained using the corrected crack length. The experimental compliance method evaluates the fracture energy using the logarithmic diagram of compliance versus crack length. In this research, the simple beam theory was used to determine the fracture energy. This was in accordance with BS 7991 standard in which the simple beam method is suggested in case that the crack propagates in a stickslip manner. According to the simple beam method, Eq. (1) can be used for obtaining the fracture energy in Mode I:

$$
G_{I C}=\frac{4 P^{2}}{E_{s} B^{2}}\left(\frac{3 a^{2}}{h^{3}}+\frac{1}{h}\right),
$$

where $G_{I C}$ is the adhesive Mode I fracture energy, $P$ is the load applied by the uniaxial testing machine, $E_{s}$ is the elastic modulus of the substrates, $B$ is the substrate width, $h$ is the substrate thickness at the crack tip, and $a$ is the crack length.

To study the effect of the MWCNT's outer diameter on the fracture energy of the adhesive, the adhesive was reinforced with MWCNTs having three outer diameters of less than 8, 20-30, and 50-80 nm each of which with three weight percentages of $0.1,0.3$, and $0.5 \mathrm{wt} \%$. Then, DCB specimens were manufactured and tested using SANTAM universal testing machine STM-150 under displacement control and at the rate of $0.5 \mathrm{~mm} / \mathrm{min}$.

A high definition camera was employed for capturing the crack growth during the test. The test setup is shown in Figure 2. To confirm the repeatability of the experimental measurements, each test was repeated at least four times.

\subsection{The effects of $M W C N T s$ on fracture energy}

The DCB specimens were tested and the loaddisplacement curves and crack growth were obtained.

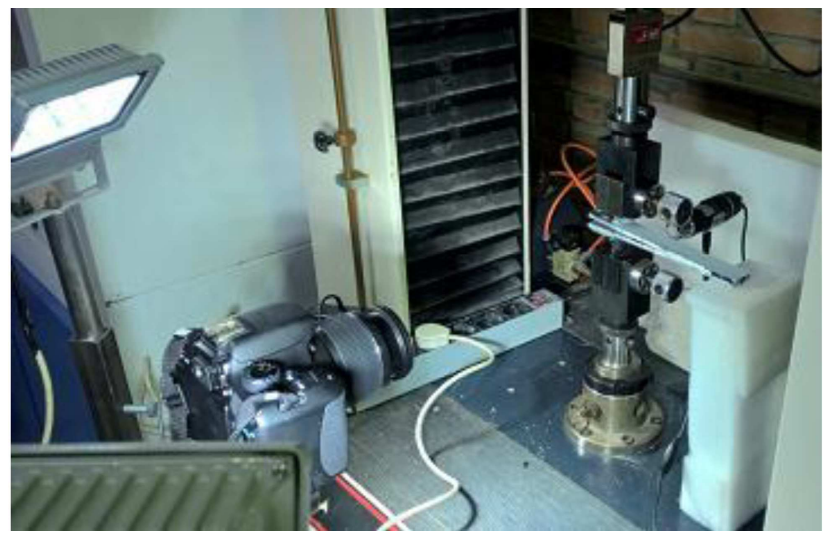

Figure 2. The test setup of DCB.

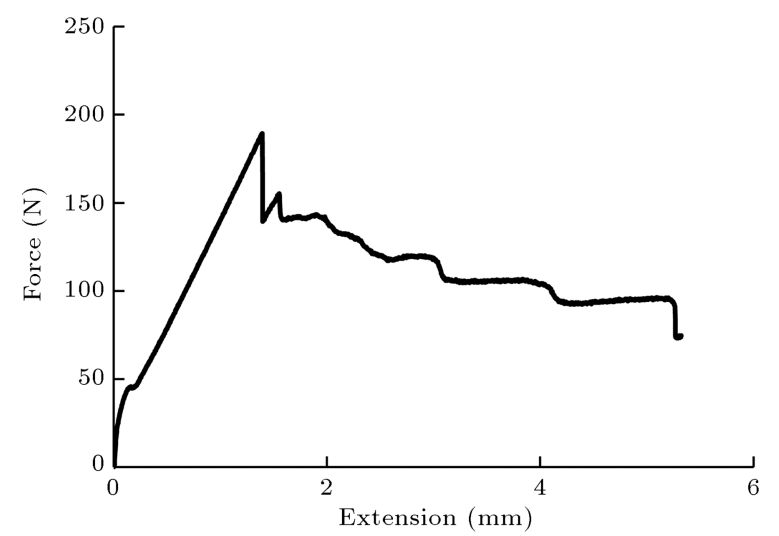

(a)

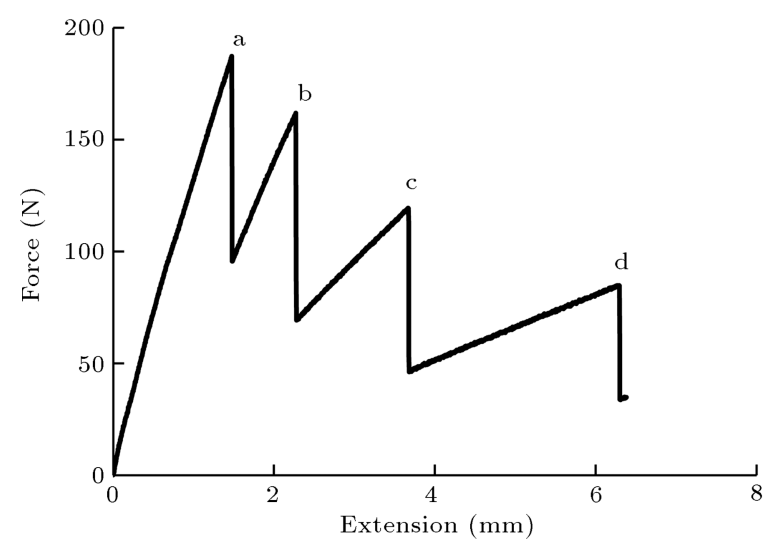

(b)

Figure 3. The typical load-displacement curves obtained for the DCB specimens: (a) Continues crack growth, and (b) stick-slip crack growth.

Two different crack growth schemes, including continuous and stick-slip crack growth patterns, were observed for different adhesive joints. Figure 3 shows two typical load-displacement curves corresponding to the continuous (Figure 3(a)) and stick-slip (Figure 3(b)) crack growth patterns. For the case of continuous crack growth, the crack length was captured by camera and the corresponding load was obtained from the loaddisplacement curve. 
According to BS 7991 standard for the stick-slip crack growth cases, as it was not possible to record the crack growth accurately in the course of testing due to the sudden crack growth, the crack length was obtained from the arrest lines on the fracture surfaces of the joints.

The peak and valley points of the loaddisplacement curves (see Figure 3(b)) obtained for the adhesive joints with stick-slip crack growth corresponded to the crack sudden growth and arrest, respectively. According to BS 7991 standard, the values of fracture energy were obtained based on the peak points.

Examining the fracture surfaces of the adhesive joints revealed that the failure mode was cohesive in the joints reinforced with 0.1 and $0.3 \mathrm{wt} \%$ MWCNTs and different outer diameters. It was found that incorporating MWCNTs with higher wt\% into the adhesive layer for reinforcement imposed detrimental effect on the adhesion between the adhesive and substrates and drove the failure to the interface. This was influenced by the MWCNT outer diameter, as the failure mode of the joints reinforced with $0.5 \mathrm{wt} \%$ MWCNTs was interfacial in the case of $20-30$ and $50-80 \mathrm{~nm}$ outer diameters, whereas it remained cohesive in the case of less than $8 \mathrm{~nm}$ outer diameters. Figure 4 illustrates the typical failure modes of interfacial (Figure 4(a)) and cohesive (Figure 4(b)) corresponding to $0.5 \mathrm{wt} \%$ MWCNTs with 50-80 nm outer diameters and $0.1 \mathrm{wt} \%$ MWCNTs with 20-30 nm outer diameters, respectively. Moreover, as shown in Figure 4, the adhesive joints had interfacial failure experienced continuous crack growth, while the adhesive joints had cohesive failure followed the stick-slip crack growth pattern.

The fracture energy values of the reinforced and unreinforced adhesives were determined using Eq. (1). The results indicated that the fracture energy value

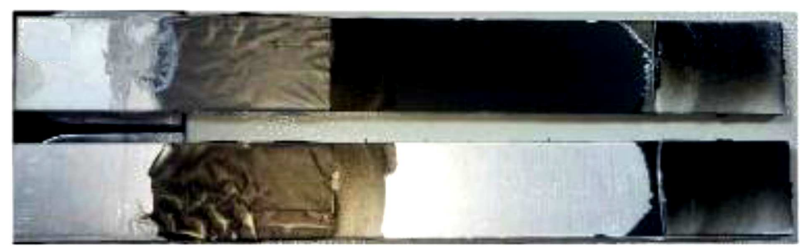

(a)

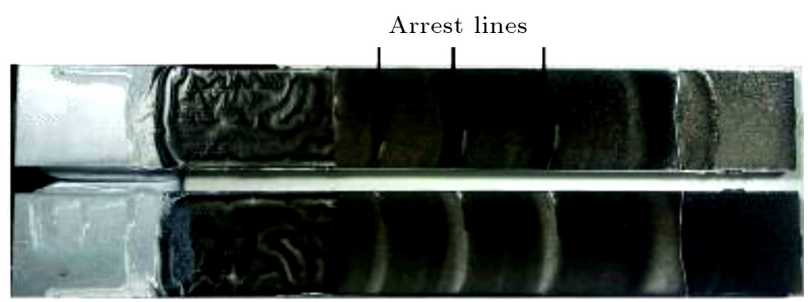

(b)

Figure 4. Typical fracture surfaces of the adhesive joints with (a) adhesive failure and (b) cohesive failure. changed as the crack grew. Figure 5 shows the fracture energy versus the crack length (R-curve) for different MWCNT sizes and weight percentages.

As can be seen in Figure 5, the R-curves obtained for $0.3 \mathrm{wt} \%$ MWCNTs with different outer diameters were above the curves of other weight percentages. This was in contrast to the R-curves of 0.5 wt\%, representing lower $G_{I C}$ values even with respect to the neat adhesive.

It should be mentioned that as $G_{I C}$ values varied by the crack length, in order to compare the fracture energy values of the adhesives with different reinforcements, the fracture energy values of all adhesives were averaged over the initial $80 \mathrm{~mm}$ crack length.

Figure 6 compares $G_{I C}$ values of the adhesives with different reinforcements. As can be seen in Figure 6, irrespective of the MWCNT outer diameter, by increasing the weight percentage up to $0.3 \mathrm{wt} \%$, the fracture energy increased and decreased afterwards. Therefore, for all MWCNT outer diameters, the toughening effect of $0.3 \mathrm{wt} \%$ MWCNT was the best, whereas the toughening effect of $0.5 \mathrm{wt} \%$ MWCNT was the worst.

The percentage differences between the fracture energies of the reinforced and neat adhesives are presented in Table 3. As can be seen from Table 3, the fracture energy increased by reducing the MWCNT outer diameter and keeping the wt\% unchanged.

Moreover, the fracture energy values of the adhesives reinforced with MWCNTs of 20-30 and 50$80 \mathrm{~nm}$ outer diameters were rather close to each other. The highest fracture energy increase was obtained for the adhesives reinforced with MWCNTs of less than $8 \mathrm{~nm}$ outer diameters and $0.3 \mathrm{wt} \%$ based on the fact that the nanotubes of smaller sizes have higher specific surface area and can provide more loci of energy absorption for a fixed weight percentage. Moreover, the results showed that increasing the weight percentage of MWCNTs above the optimum value not only degraded the cohesion due to the MWCNTs agglomeration, but also degraded the interface as well. This can be concluded by comparing the fracture surfaces and the fact that failure occurred at the interface in $0.5 \mathrm{wt} \%$ reinforcements of bigger MWCNTs.

The results showed that the maximum improvements of the fracture energy for different MWCNT sizes of less than 8, 20-30, and 50-80 nm were $58.4 \%, 20.4 \%$,

Table 3. Percentage difference between the fracture

\begin{tabular}{cccc} 
energy values of the neat and reinforced adhesives. \\
\cline { 2 - 4 } Outer & \multicolumn{3}{c}{ \%Difference } \\
\cline { 2 - 4 } diameter & $\mathbf{0 . 1} \mathbf{w t \%}$ & $\mathbf{0 . 3} \mathbf{w t \%}$ & $\mathbf{0 . 5} \mathbf{w t \%}$ \\
\hline$<8 \mathrm{~nm}$ & $22.8 \%$ & $58.4 \%$ & $4.3 \%$ \\
$20-30 \mathrm{~nm}$ & $7.4 \%$ & $20.4 \%$ & $-2.0 \%$ \\
$50-80 \mathrm{~nm}$ & $7.1 \%$ & $20.1 \%$ & $-16.2 \%$ \\
\hline
\end{tabular}




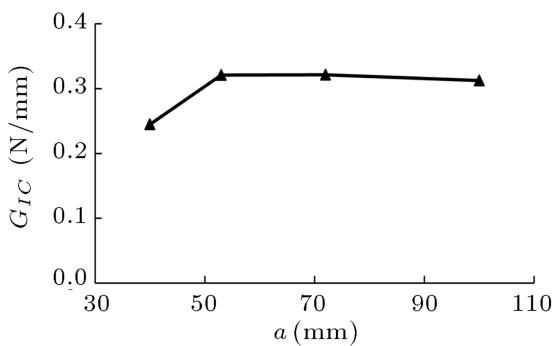

(a)

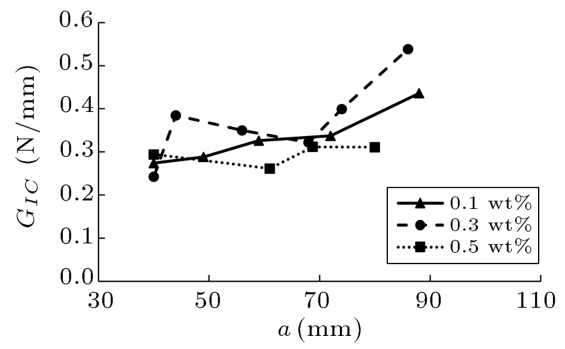

(c)

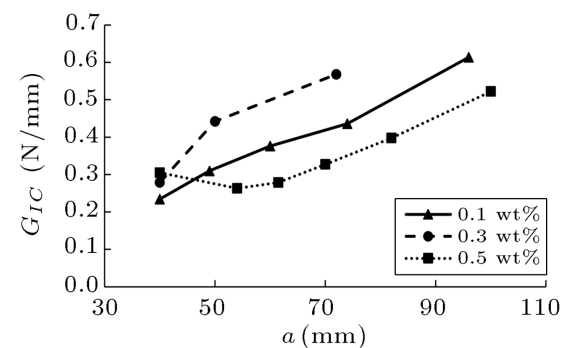

(b)

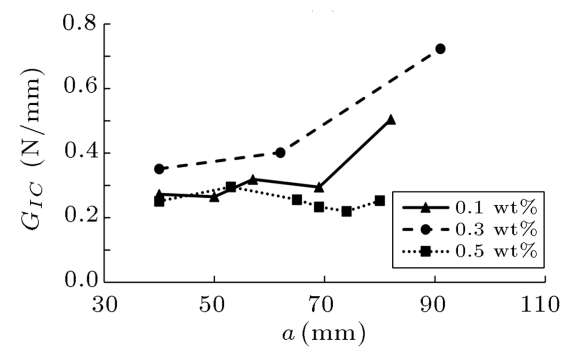

(d)

Figure 5. Fracture energy versus crack length: (a) Neat adhesive and the reinforced adhesive with MWCNTs of different diameters, (b) $<8 \mathrm{~nm}$, (c) 20-30 nm, and (d) 50-80 $\mathrm{nm}$.

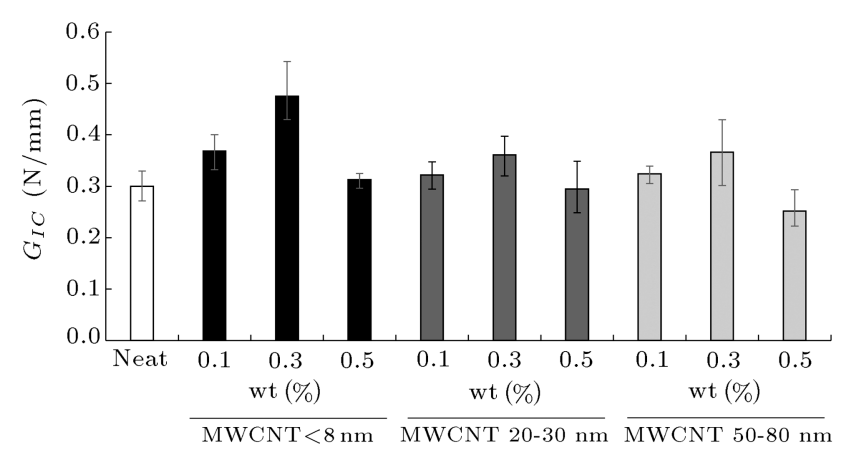

Figure 6. Comparison between $G_{I C}$ values of the adhesives with different reinforcements.

and $20.1 \%$, respectively. Moreover, the fracture energy for the specimens, containing MWCNTs of sizes 2030 and $50-80 \mathrm{~nm}$ and weight percentage of $0.5 \mathrm{wt} \%$, decreased compared to the neat adhesive.

\subsection{The SEM micrographs}

In order to understand the micro- and nanomechanisms and such resulting differences in the fracture energies of the adhesive joints, the fracture surfaces were examined by scanning electron microscopy. SEM observations were carried out with VEGAII TESCAN operating at $30 \mathrm{kV}$ voltage. It was found that the roughness of the fracture surfaces can be considered as an important factor in increasing the fracture energy values. The SEM images of the fracture surfaces of the neat and reinforced adhesive joints are depicted in Figure 7.

As seen in Figure 7, as the roughness of the fracture surfaces of the adhesive joints increased because of the addition of MWCNTs to the adhesive, the fracture energy of the specimens increased. This was due to the fact that as the surface roughness increased, the crack grew through a longer path. For all cases, the fracture surfaces of the adhesives, reinforced by MWCNTs, are rougher compared to the neat adhesives. Moreover, as can be seen in Figure 7(b), the fracture surface of the adhesive reinforced with $0.3 \mathrm{wt} \%$ of MWCNTs having outer diameter of less than $8 \mathrm{~nm}$ was the roughest compared to the other cases. This can be accounted for as one of the main reasons of why this adhesive (i.e., the adhesive reinforced with $0.3 \mathrm{wt} \%$ of MWCNTs with outer diameter of less than $8 \mathrm{~nm}$ ) showed the highest fracture energy compared to the other adhesives (see Figure 6). However, for the adhesives reinforced with 0.5 wt\% MWCNTs, the MWCNTs agglomerations were observed. These MWCNTs agglomerations gave rise to high stress concentration in the epoxy adhesive, which was the main reason for the fracture energy decrease in the $0.5 \mathrm{wt} \%$. Figure 8 illustrates the MWCNTs agglomerations in the adhesive joints reinforced with $0.5 \mathrm{wt} \%$ and different outer diameters.

By adding the MWCNTs to the adhesive layer, several mechanisms were observed in the fracture surfaces that caused the increase of the fracture energy. The MWCNT debonding, pullout and crack bridging mechanisms were observed on the fracture surfaces of the adhesive reinforced with MWCNTs. Each of these mechanisms can lead to higher energy absorption and an increase in the fracture energy.

The nanotubes in the reinforced adhesive, through their interfacial bonding with the matrix, can contribute to the load bearing of the adhesive joints. The interfacial shear stresses may result in MWCNTs pullout from the adhesive. This mechanism has the capability of absorbing considerable energy, and 


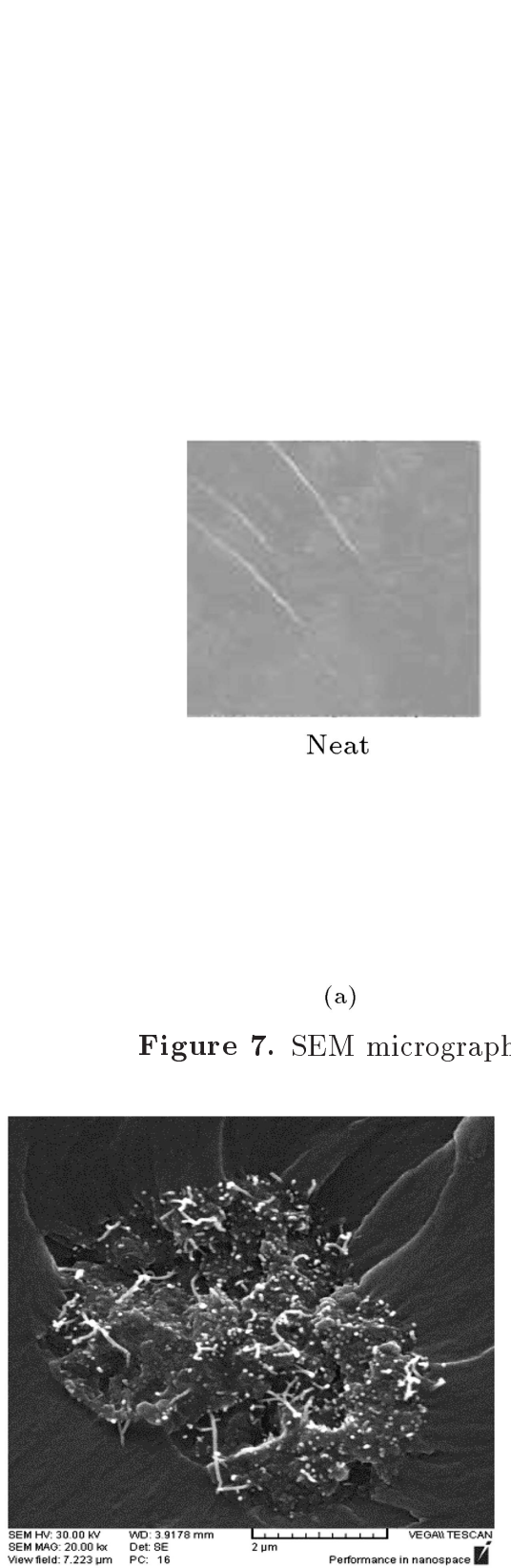

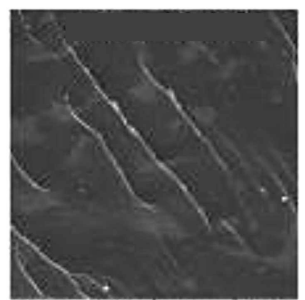

$<8 \mathrm{~nm}, 0.1 \mathrm{wt} \%$

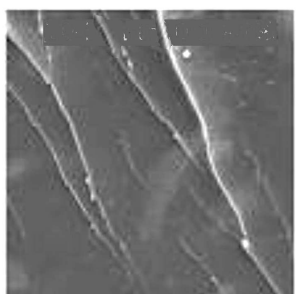

20-30 nm, $0.1 \mathrm{wt} \%$

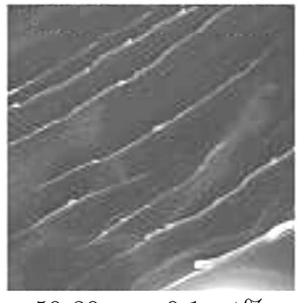

50-80 nm, $0.1 \mathrm{wt} \%$

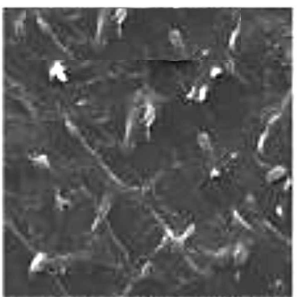

$<8 \mathrm{~nm}, 0.3 \mathrm{wt} \%$

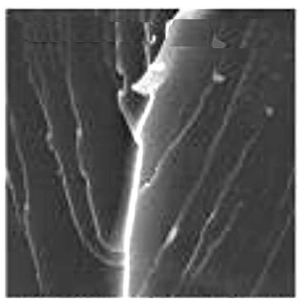

$20-30 \mathrm{~nm}, 0.3 \mathrm{wt} \%$

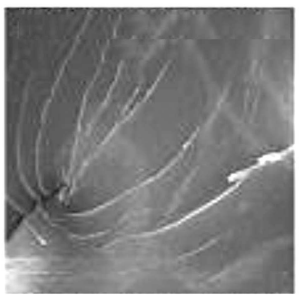

$50-80 \mathrm{~nm}, 0.3 \mathrm{wt} \%$

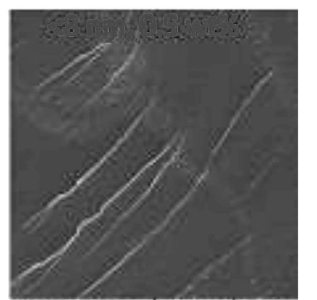

$<8 \mathrm{~nm} .0 .5 \mathrm{wt} \%$

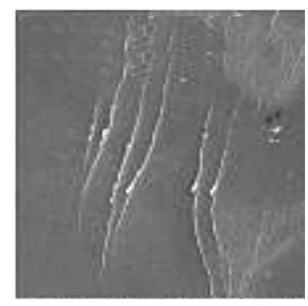

$20-30 \mathrm{~nm}, 0.5 \mathrm{wt} \%$

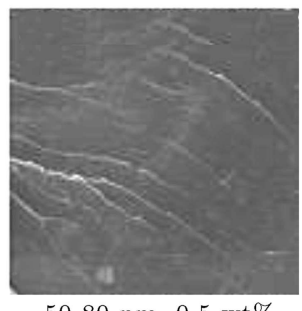

50-80 nm, $0.5 \mathrm{wt} \%$

(b)

(a) Neat adhesive, and (b) reinforced adhesives.

(a)

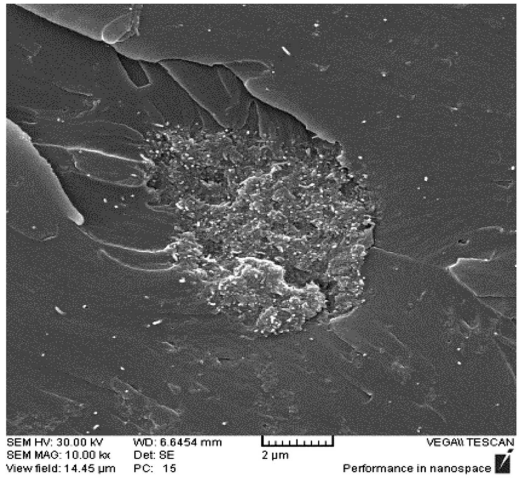

(b)

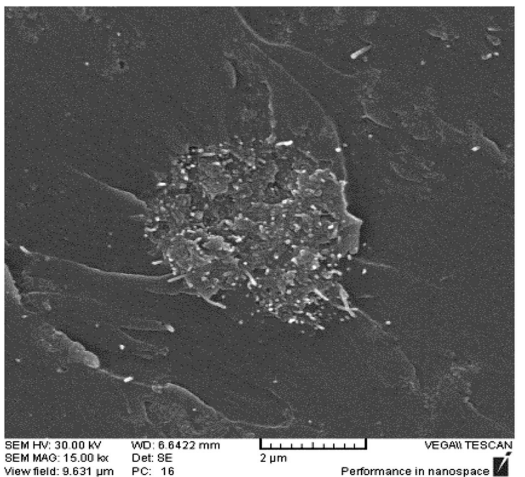

(c)

Figure 8. The MWCNT agglomerations for the adhesive reinforcement of $5.0 \mathrm{wt} \%$ MWCNT: (a) $<8 \mathrm{~nm}$, (b) $20-30 \mathrm{~nm}$, and (c) 50-80 nm.

consequently increasing the fracture energy. Figure 9 shows debonding, pullout, and crack bridging of the MWCNTs in different weight percentages and different outer diameters.

\section{Numerical}

\subsection{Finite-element model}

The finite-element analyses were utilized for investigating the effects of outer diameter and weight percentage of MWCNTs on the damage behavior of the adhesive joints. The progressive damage in materials can be sim- ulated using the cohesive zone model by combining the concepts of continuum damage and fracture mechanics. The cohesive zone model uses the traction-separation law to simulate damage initiation and evolution. In this research, a bilinear traction-separation law was used to analyze the damage behavior of the adhesives.

A bilinear traction-separation law is shown in Figure 10. The bilinear traction-separation law can be defined by three parameters including initial stiffness $\left(k\left(\mathrm{~N} / \mathrm{mm}^{3}\right)\right)$, cohesive strength $\left(t_{0}(\mathrm{MPa})\right)$, and fracture energy $\left(G_{I C}(\mathrm{~N} / \mathrm{mm})\right)$. The initial stiffness is the initial slop of the traction-separation curve, 

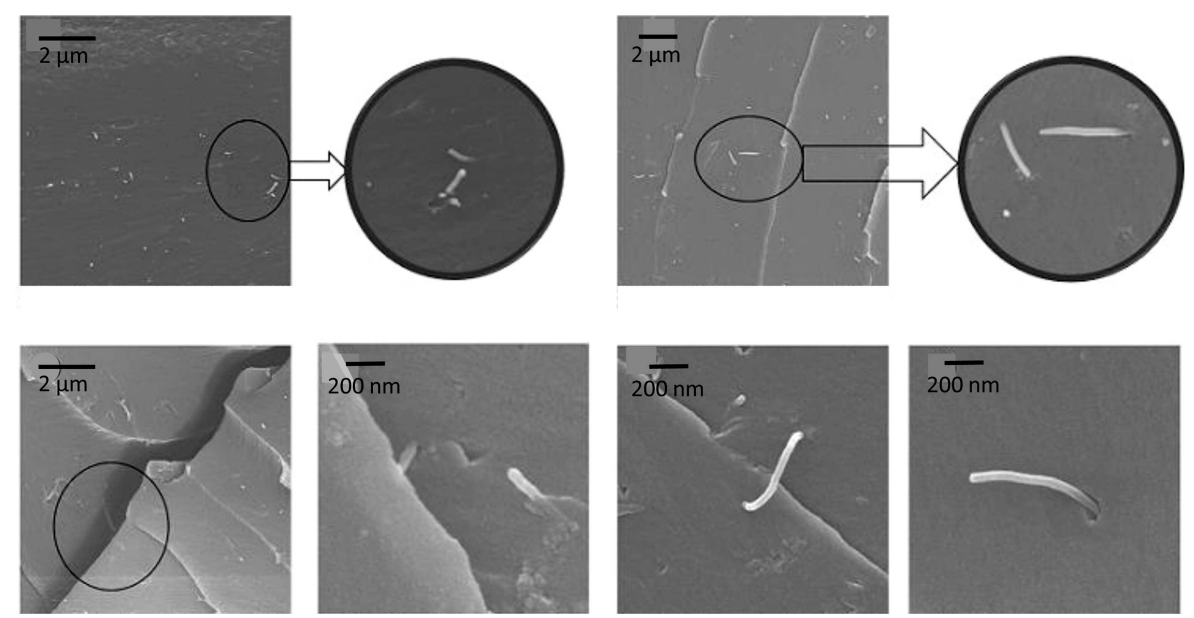

Figure 9. SEM images of the fracture micro-mechanisms of the reinforced adhesives including debonding, pullout, and crack bridging of MWCNTs.

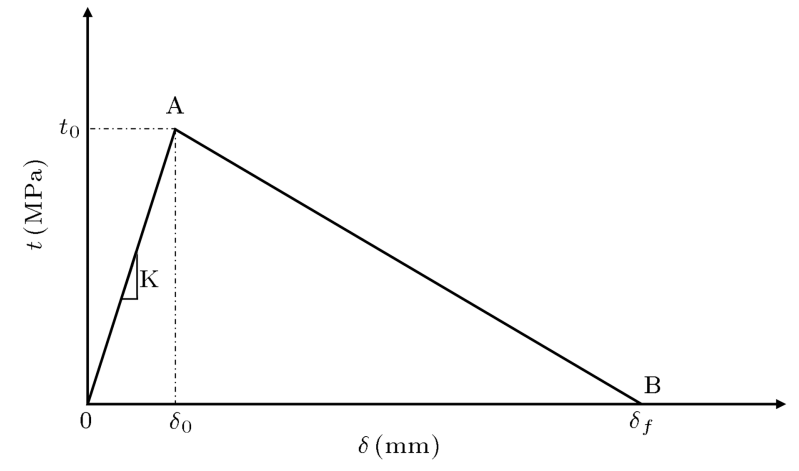

Figure 10. A bi-linear traction-separation law.

the cohesive strength is the maximum traction, and the fracture energy is the area beneath the tractionseparation curve.

As seen in Figure 10, by increasing separation $(\delta)$, traction $(t)$ increases initially, reaching a maximum followed by a decrease to zero traction. The damage initiates from point A (see Figure 10), and it evolves to fully developed damage at point B, representing that the material cannot sustain any stress at that point representing crack growth.

The initial stiffness value should be considered large enough to prevent the cohesive elements affecting the overall compliance of the specimen before damage initiation [19]. However, it cannot be infinitely large as it leads to numerical ill-conditioning. The initial stiffness was considered $10000 \mathrm{~N} / \mathrm{mm}^{3}$ in this research. The fracture energy values were obtained experimentally, as discussed in Section 3.3. The cohesive strength was determined so that the numerical loaddisplacement curve correlated with the experimental curve.

In finite-element modeling, the substrates were modeled by the 4-node plain strain elements (CPE4) and the adhesive layer was modeled using 2D dimensional cohesive elements (COH2D4). Moreover, a mesh

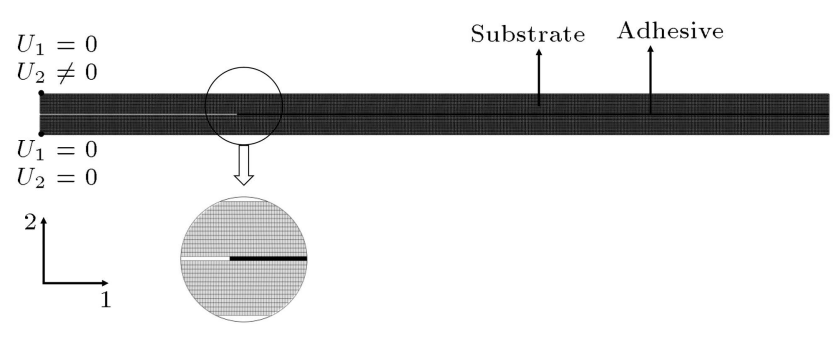

Figure 11. Finite-element model .

convergence study was undertaken to determine the proper element size. Figure 11 illustrates the FE model of the DCB specimen.

\subsection{Numerical results and discussions}

The comparisons between the experimental and numerical load-displacement curves of the adhesive joints experiencing stick-slip and continuous crack growth schemes are shown in Figure 12. As can be seen from Figure 12(a), in the case of stick-slip crack growth, the predicted curve correlated well with the peak points of the experimental curve. This was basically because, according to BS 7991 standard, the fracture energies were obtained based on the peak points.

The CZM parameters, including the initial stiffness, the cohesive strength, and the fracture energy, obtained for the neat and reinforced adhesives are presented in Table 4.

The bilinear traction-separation curves obtained for the adhesives reinforced with MWCNTs of less than $8 \mathrm{~nm}$ and various wt\% are shown in Figure 13.

According to Figure 13, as two parameters of the fracture energy and the cohesive strength changed, the base of the triangle varied accordingly. The final separation $\left(\delta_{f}\right.$ in Figure 10) can be related to the process zone length. It was seen that as the final separation increased, the process zone length in the FE model increased accordingly. As seen in Figure 13 and $\mathrm{FE}$ analyses, as the weight percentage increased 
Table 4. The cohesive zone model's parameters of the neat and reinforced adhesives.

\begin{tabular}{ccccc}
\hline Adhesive & $\mathbf{w t} \%$ & $\boldsymbol{t}_{\mathbf{0}}(\mathbf{M P a})$ & $\boldsymbol{K}\left(\mathbf{N} / \mathbf{m m}^{\mathbf{3}}\right)$ & $\boldsymbol{G}_{\boldsymbol{I C}}(\mathbf{N} / \mathbf{m m})$ \\
\hline Neat & - & 19 & 10000 & 0.2997 \\
\hline \multirow{2}{*}{ MWCNT < 8 nm } & 0.1 & 11 & 10000 & 0.3683 \\
& 0.3 & 11 & 10000 & 0.4749 \\
& 0.5 & 20 & 10000 & 0.3126 \\
MWCNT 20-30 nm & 0.1 & 20 & 10000 & 0.3220 \\
& 0.5 & 22 & 10000 & 0.3610 \\
& 0.1 & 18 & 10000 & 0.2946 \\
MWCNT 50-80 nm & 0.3 & 18 & 10000 & 0.3210 \\
& 0.5 & 20 & 10000 & 0.3600 \\
\hline
\end{tabular}

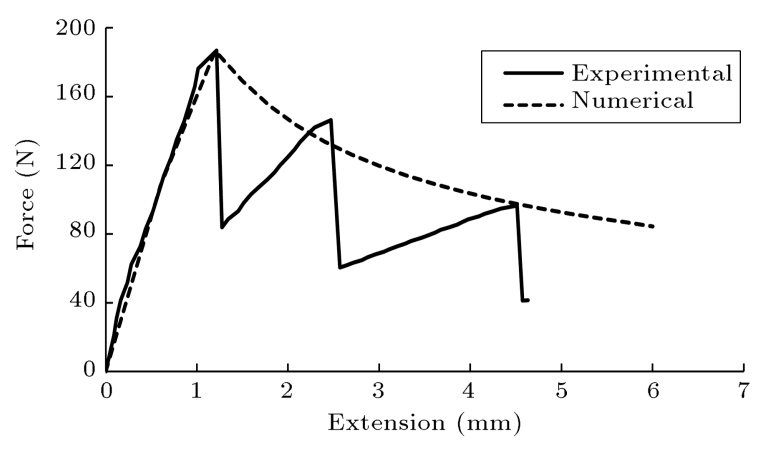

(a)

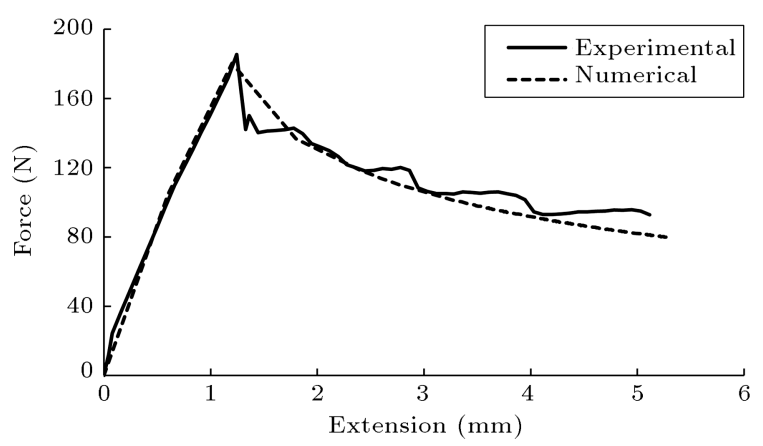

(b)

Figure 12. Comparison between the numerical and experimental load-displacement curves: (a) Stick-slip crack growth, and (b) continuous crack growth..

from $0 \%$ to $0.1 \%$, the process zone length increased until it reached its maximum value at $0.3 \mathrm{wt} \%$. By increasing the weight percentage beyond this value, the process zone length decreased at $0.5 \mathrm{wt} \%$. At $0.5 \mathrm{wt} \%$, the agglomeration of MWCNTs affected the process zone. The similar trends were also observed for the other MWCNT outer diameters.

Figure 14 compares the traction-separation curves of the adhesive reinforced with $0.3 \mathrm{wt} \%$ MWCNTs and different outer diameters. As can be seen from Figure 14, the process zone length was also influenced by the MWCNT outer diameter. The MWCNTs with

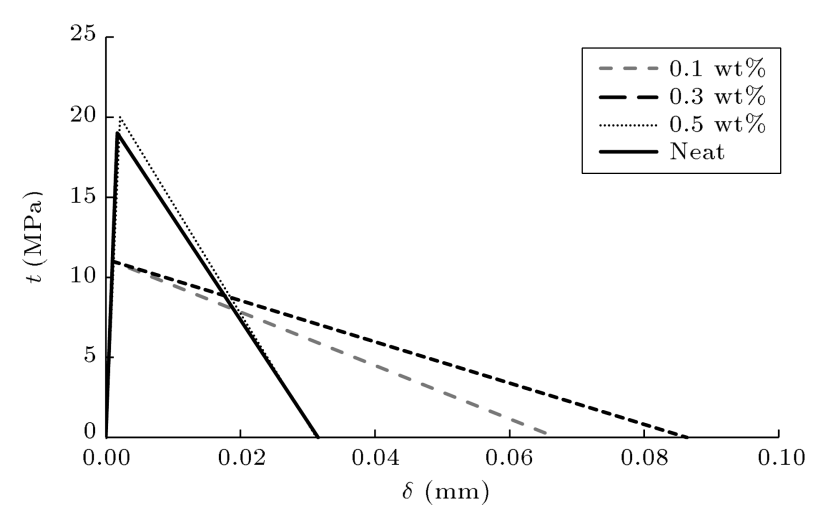

Figure 13. The traction-separation curves of the adhesives reinforced with MWCNTs $<8 \mathrm{~nm}$ and various wt $\%$.

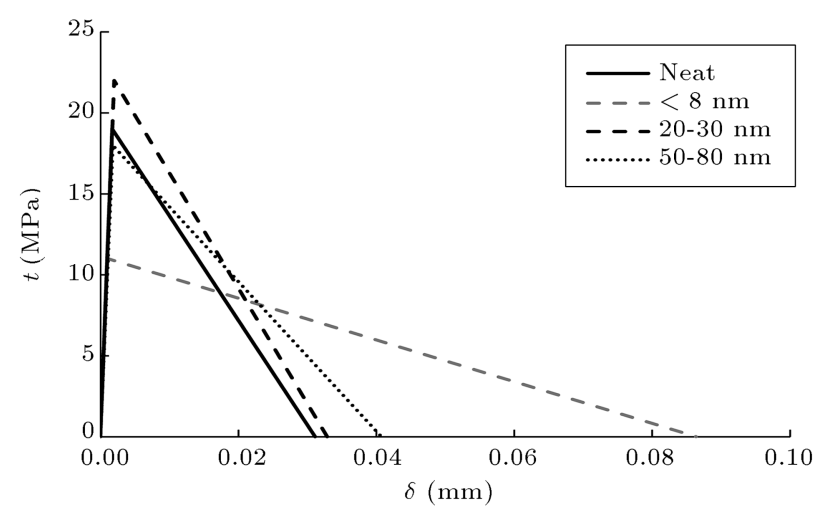

Figure 14. The traction-separation curves of the adhesives reinforced with $0.3 \mathrm{wt} \%$ MWCNTs and various sizes.

a smaller diameter (less than $8 \mathrm{~nm}$ ) represented longer process zone compared to that with other sizes.

\section{Conclusions}

In this paper, the effect of the MWCNT's outer diameter was investigated on the fracture behavior of 
the adhesive joints. The adhesive joints were reinforced with MWCNTs with three different outer diameters of less than 8, 20-30, and 50-80 $\mathrm{nm}$. It was found that the MWCNT size influenced the fracture energy values and the damage behavior of the adhesive considerably. The maximum fracture energy improvement of $58.4 \%$ compared to the neat adhesive was obtained for the adhesive reinforced by MWCNTs of less than $8 \mathrm{~nm}$ diameter and $0.3 \mathrm{wt} \%$. The experimental results showed that incorporating higher amount of MWCNTs imposed a decreasing effect on the fracture energy. This decreasing effect was found to be higher in the case of MWCNTs with larger diameters. Moreover, the SEM micrographs showed several fracture mechanisms such as the MWCNTs pullout, debonding, and crack bridging causing fracture energy improvement. In addition, a direct relationship was found between the roughness of the fracture surface and the fracture energy values. Furthermore, the effects of the size and weight percentage of MWCNTs on damage behavior of the adhesive were studied numerically using the cohesive zone model. The maximum fracture process zone length was found for the adhesive reinforced by MWCNTs with outer diameters of less than $8 \mathrm{~nm}$ and $0.3 \mathrm{wt} \%$.

\section{Acknowledgement}

The authors would like to thank the Iran National Science Foundation (INSF) for the financial support of this study.

\section{Nomenclature}

$\begin{array}{ll}a & \text { Crack length } \\ B & \text { Substrate width } \\ E_{s} & \text { Elastic modulus of the substrates } \\ G_{I C} & \text { Mode I fracture energy } \\ h & \text { Substrate thickness } \\ k & \text { Initial stiffness of traction-separation } \\ & \text { law } \\ P & \text { Applied load } \\ t & \text { Traction } \\ t_{0} & \text { Cohesive strength } \\ \delta & \text { Separation } \\ \delta_{f} & \text { Final separation }\end{array}$

\section{References}

1. Hartwig, A., Lühring, A. and Trautmann, J. "Spheroidal nanoparticles in epoxide-based adhesives", Macromolecular Materials and Engineering, 294(6-7), pp. 363-379 (2009).

2. Meng, Q., Wang, C.H., Saber, N. et al. "Nanosilica- toughened polymer adhesives", Materials \& Design, 61, pp. 75-86 (2014).

3. Kinloch, A., Lee, J., Taylor, A., Sprenger, S., Eger, C. and Egan, D. "Toughening structural adhesives via nano-and micro-phase inclusions", The Journal of Adhesion, 79(8-9), pp. 867-873 (2003).

4. Kim, B.C. and Park, S.W. "Fracture toughness of the nano-particle reinforced epoxy composite", Composite Structures, 86(1), pp. 69-77 (2008).

5. Wernik, J. and Meguid, S. "On the mechanical characterization of carbon nanotube reinforced epoxy adhesives", Materials \& Design, 59, pp. 19-32 (2014).

6. Chatterjee, S., Nafezarefi, F., Tai, N., Schlagenhauf, L., Nüesch, F. and Chu, B. "Size and synergy effects of nanofiller hybrids including graphene nanoplatelets and carbon nanotubes in mechanical properties of epoxy composites", Carbon, 50(15), pp. 5380-5386 (2012).

7. Yasaee, M., Bond, I., Trask, R. and Greenhalgh, E. "Mode I interfacial toughening through discontinuous interleaves for damage suppression and control", Composites Part A: Applied Science and Manufacturing, 43(1), pp. 198-207 (2012).

8. Sun, Z., Jeyaraman, J., Sun, S., Hu, X. and Chen, H. "Carbon-fiber aluminum-foam sandwich with short aramid-fiber interfacial toughening", Composites Part A: Applied Science and Manufacturing, 43(11), pp. 2059-2064 (2012).

9. Dittanet, P. and Pearson, R.A. "Effect of silica nanoparticle size on toughening mechanisms of filled epoxy", Polymer, 53(9), pp. 1890-1905 (2012).

10. Zamanian, M., Mortezaei, M., Salehnia, B. and Jam, J. "Fracture toughness of epoxy polymer modified with nanosilica particles: Particle size effect", Engineering Fracture Mechanics, 97, pp. 193-206 (2013).

11. Gojny, F.H., Wichmann, M.H., Fiedler, B. and Schulte, K. "Influence of different carbon nanotubes on the mechanical properties of epoxy matrix compositesa comparative study", Composites Science and Technology, 65(15), pp. 2300-2313 (2005).

12. Meguid, S. and Sun, Y. "On the tensile and shear strength of nano-reinforced composite interfaces", $M a$ terials \& Design, 25(4), pp. 289-296 (2004).

13. Meng, Q., Araby, S., Saber, N., et al. "Toughening polymer adhesives using nanosized elastomeric particles", Journal of Materials Research, 29(05), pp. 665674 (2014).

14. Gude, M., Prolongo, S., Gómez-del Río, T. and Urena, A. "Mode-I adhesive fracture energy of carbon fibre composite joints with nanoreinforced epoxy adhesives", International Journal of Adhesion and Adhesives, 31(7), pp. 695-703 (2011).

15. De Moura, M., Gonçalves, J., and Magalhães, A. "A straightforward method to obtain the cohesive laws of bonded joints under mode I loading", International Journal of Adhesion and Adhesives, 39, pp. 54-59 (2012). 
16. Khoramishad, H., Crocombe, A., Katnam, K. and Ashcroft, I. "Fatigue damage modelling of adhesively bonded joints under variable amplitude loading using a cohesive zone model", Engineering Fracture Mechanics, 78(18), pp. 3212-3225 (2011).

17. Han, X., Crocombe, A., Anwar, S. and Hu, P. "The strength prediction of adhesive single lap joints exposed to long term loading in a hostile environment", International Journal of Adhesion and Adhesives, 55, pp. 1-11 (2014).

18. UHU plus endfest 300, Technical Data Sheet, UHU GmbH \& Co. KG - P.O. Box 1552, D-77813 Bühl.

19. Moslemi, M. and Khoshravan, M. "Cohesive zone parameters selection for Mode-I prediction of interfacial delamination", Strojniški vestnik-Journal of Mechanical Engineering, 61(9), pp. 507-516 (2015).

\section{Biographies}

Hadi Khoramishad is an Assistant Professor of Mechanical Engineering at Iran University of Science and Technology where he has been a faculty member since 2011. He received his $\mathrm{PhD}$ degree from University of Surrey, UK. He also completed his MSc and BSc degrees in Iran University of Science and Technology and Amirkabir University, Iran, respectively. His fields of interests are adhesively bonded structures, nanoadhesives and composites, damage (fatigue, creep, impact and environmental) characterization and modeling in polymeric materials.

Moein Khakzad received his MSc degree in Mechanical Engineering from Iran University of Science and Technology in 2016. He also received his BSc degree in Mechanical Engineering from Foulad Institute of Technology, Iran, in 2012. His fields of study are solid mechanics and material science. He has 2 ISI and 1 ISC papers submitted.

Mohammad Fasihi is an Assistant Professor of Chemical Engineering at Iran University of Science and Technology where he has been a faculty member since 2013. He has BSc, MSc, and PhD degrees in Polymer Engineering from Amirkabir University of Technology, Tehran, Iran. His research interests are in the areas of thermoplastic blends, foams, and composites. 